\title{
STATUS MUTU AIR DAN TINGKAT KESUBURAN PERAIRAN BENGAWAN JERO KECAMATAN TURI KABUPATEN LAMONGAN
}

\author{
Fuquh Rahmat Shaleh* \\ *Fakultas Perikanan Universitas Islam Lamongan \\ Jl. Veteran no. 53A Lamongan Phone/Fax.0322_324706
}

\begin{abstract}
ABSTRAK
Pemanfaatan Bengawan Jero (Bono Rowo) di Kabupaten Lamongan memilikii fungsi strategis dalam memenuhi kebutuhan hidup masyarakat antara lain dii bidang perikanan, pertanian, maupun keperluan rumah tangga seperti mencuci dan mandi. Status mutu air dan tingkat kesuburan perairan di Bengawan Jero perlu diketahui agar pengelolaan perairan di kawasan tersebut lestari serta berkelanjutan agar terciptanya kesejahteraan masyarakat. Penelitian inii dilaksanakan pada Juli 2017 di Kecamatan Turi. Metode yang digunakan adalah metode deskriptif secara logik dengan analisis data status mutu air menggunkan metode STORET berdasarkan Kepmen LH Nomor 115 Tahun 2003 serta Carlson Trophic State Index (TSI) untuk mengetahui tingkat kesuburan perairan. Berdasarkan hasil penelitian, status mutu Bengawan Jero dalam kondisi buruk (tercemar berat) pada Kelas I dan II, sedangkan pada kelas III dalam kondisi sedang (tercemar sedang). Tingkat kesuburan perairan di Bengawan Jero telah dalam kondisi hipereutrofik atau kondisi dimana unsur haranya sangat tinggi. Sehingga diperlukanya penanggulangan eutrofikasi dengan salah satu cara penebaran ikan pemakan plankton (plankton feeder)
\end{abstract}

\section{Kata Kunci : Bengawan Jero, Status Mutu Air, Tingkat Kesuburan Perairan, Kabupaten Lamongan}

\section{PENDAHULUAN}

Kabupaten Lamongan merupakan kabupaten yang menjadi hulu dari aliran Sungai Bengawan Solo. Topografi Kabupaten Lamongan ada beberapa kawasan yang memiliki ketinggian permukaan tanah lebih rendah dari ketinggian Sungai Bengawan Solo. Hal inilah yang menyebabkan kawasan tersebut menjadi langganan banjir tiap tahun.. Kawasan ini disebut Bengawan Jero (Bono Rowo). Perairan Bengawan Jero (Bono Rowo) merupakan daerah hamparan wilayah yang berada pada 6 kecamatan yaitu Kecamatan Turi, Karanggeneng, Kalitengah, Karangbinangun, Glagah dan Deket yang lokasinya berada di sebelah utara jalan raya Gresik - Babat. Bengawan Jero (Bono
Rowo) merupakan sumber kehidupan bagi masyarakat di enam kecamatan tersebut.

Pemanfaatan Bengawan Jero (Bono Rowo) di Kecamatan Turi memiliki fungsi strategis dalam memenuhi kebutuhan hidup masyarakat antara lain di bidang perikanan, pertanian, maupun keperluan rumah tangga seperti mencuci dan mandi. Pemanfaatan air untuk keperluan rumah tangga perlu diketahui status mutu airnya agar mampu menghindari, mencegah dan menanggulangi akibat dari pencemaran air yaitu terjangkitnya penyakit. Menurut KepMen LH No. 115 tahun 2003, Status mutu air adalah tingkat kondisi mutu air yang menunjukkan kondisi cemar atau kondisi baik pada suatu sumber air dalam waktu tertentu dengan membandingkan baku mutu air yang ditetapkan. Menurut Walukow 
(2010), akibat yang ditimbulkan oleh pencemaran air antara lain: a). Terganggunya kehidupan organisme air karena berkurangnya kandungan oksigen; b). Terjadinya ledakan populasi ganggang dan tumbuhan air (eutrofikasi); dan c) Pendangkalan dasar perairan.

Dalam pemanfaatan perairan di bidang perikanan perlu diketahuinya tingkat kesuburan perairan sebagai penentu pemilihan pengembangan perikanan yang sesuai yaitu perikanan tangkap atau budidaya. Perikanan di Bengawan Jero Kecamatan Turi dilakukan tanpa mengetahui tingkat kesuburan perairan, sehingga perikanan budidaya sering mengalami kegagalan dan hasil perikanan tangkap yang sedikit. Oleh karena itu diperlukannya kajian mengenai status mutu air dan tingkat kesuburan perairan di Rawa Bengawan Jero di Kecamatan Turi Kabupaten Lamongan.

\section{METODE PENELITIAN}

Penelitian ini dilaksanakan di Bengawan Jero (Bono Rowo) Kecamatan Turi Kabupaten Lamongan pada bulan Juli 2017. Penelitian ini menggunakan tehnik sampel acak berstrata atau Stratified Random Sampling pada tiga stasiun yaitu di Desa Kemlagi Lor, Desa Pomahan Janggan dan Desa Kepudi Bener yang setiap stasiun dilakukan tiga kali pengukuran (Gambar 1). Pengambilan stasiun pertama di Dusun Kiringan Desa Kemlagi Lor dikarenakan adanya kegiatan pasar di bantaran sungai. Stasiun kedua di Dusun Janggan Desa Pomahan Janggan merupakan titik tengah Bengawan Jero (Bono Rowo) yang ada di Kecamatan Turi serta pertemuan dengan Kali Plalangan, dan Stasiun ketiga berada di Dusun Mbeneran Desa Kepudi Bener yang jauh dari pemukiman

Parameter yang diamati antara lain suhu, kecerahan, oksigen terlarut,pH, nitrat, amoniak, dan total fosfor. Analisis kualitas air dilakukan di Laboratorium Fakultas Perikanan Universitas Islam Lamongan dan Dinas Perikanan Kabupaten Lamongan. Angka klorofil bisa diketahui melalui total fosfor dengan persamaan Walmsley dan Thorthon (1984) dalam Beveridge (2004) $[\mathrm{Chl}]=0,416 \mathbf{P}^{0,675}, \mathrm{r}=0.84 \quad$ (Walmsley and Thorton ,1984) 


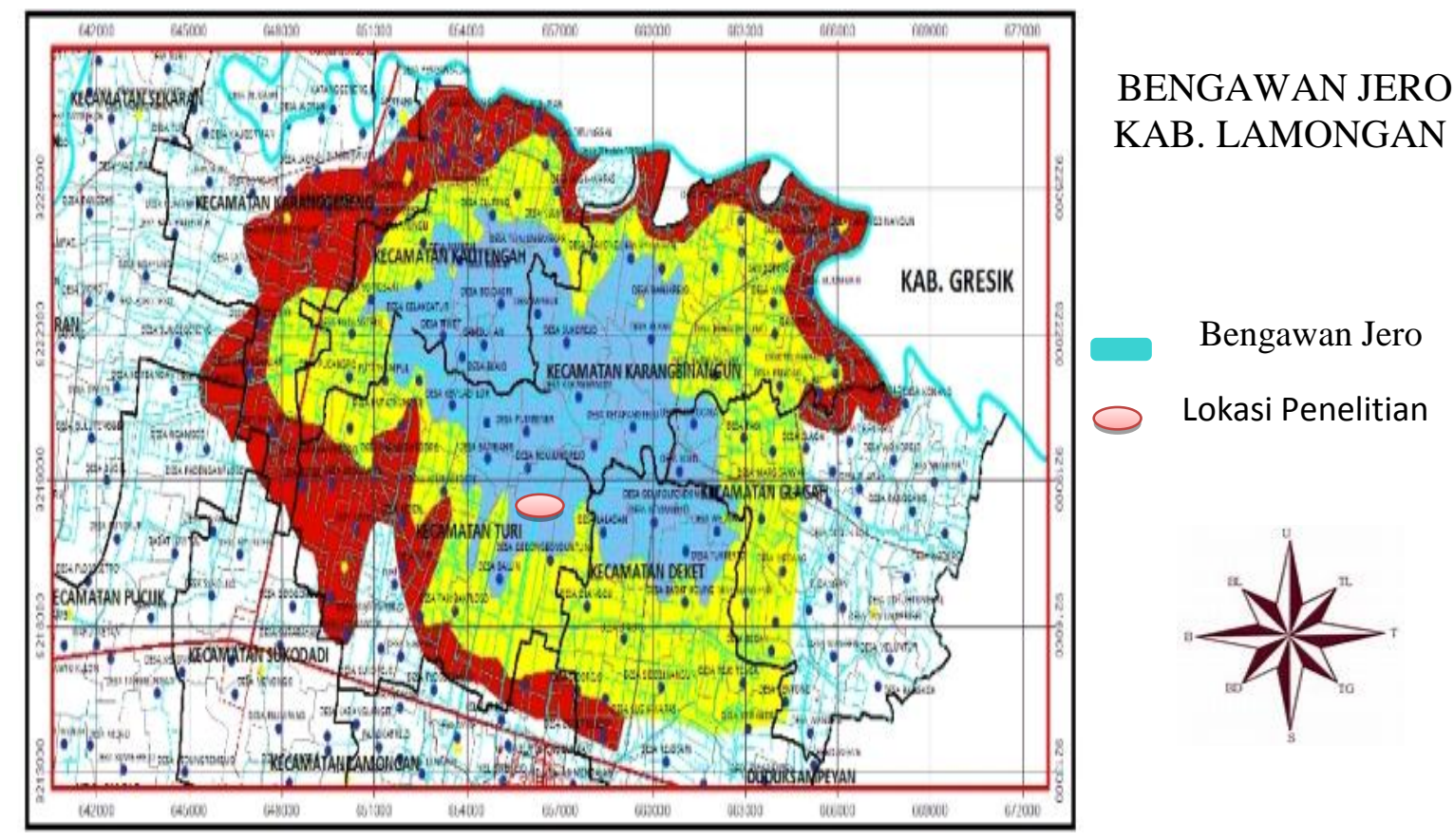

Gambar 1. Lokasi Bengawan Jero Kab Lamongan

\section{Analisis data}

Menurut KepMen LH Nomor 115 Tahun 2003, metode STORET merupakan salah satu metode untuk menentukan status mutu air yang umum digunakan. Dengan metode ini dapat diketahui tingkatan klasifikasi mutu parameter yang telah memenuhi atau melampaui baku mutu air. Penentuan mutu air dengan metode STORET sebagai berikut:

a. Membandingkan data hasil pengukuran masing-masing parameter fisika, kimia dan biologi yang di uji dengan nilai baku mutu yang sesuai dengan kelas air

b. Jika hasil pengukuran memenuhi baku mutu maka diberi skor 0, apabila tidak memenuhi baku mutu maka diberi skor berdasarkan ketentuan Tabel 1 .

c. Penentuan status mutu air didapatkan dari penjumlahan skor dan diklasifikasikan sesuai pada Tabel 2.
Tabel 1. Penentuan sistem nilai metode STORET

\begin{tabular}{ccccc}
\hline Jumlah & \multirow{2}{*}{ Nilai } & \multicolumn{3}{c}{ Parameter } \\
Percontohan & & Fisika & Kimia & Biologi \\
\hline \multirow{3}{*}{ kurang 10 } & Maksimum & -1 & -2 & -3 \\
& Minimum & -1 & -2 & -3 \\
& Rata-rata & -3 & -6 & -9 \\
Lebih dari & Maksimum & -2 & -4 & -6 \\
\cline { 2 - 5 } 10 & Minimum & -2 & -4 & -6 \\
& Rata-rata & -6 & -12 & -12 \\
\hline
\end{tabular}

Tabel 2. Klasifikasi status mutu air berdasarkan penilaian Metode Storet

\begin{tabular}{cll}
\hline Kelas & \multicolumn{1}{c}{ Status } & \multicolumn{1}{c}{ Skor } \\
\hline A & Baik Sekali & Skor $=0$ \\
B & Baik & Skor-1 sampai -10 \\
C & Sedang & Skor -11 sampai -30 \\
D & Buruk & Skor lebih -30 \\
\hline
\end{tabular}

Tingkat kesuburan perairan dapat diketahui melalui Carlson Trophic State Index (TSI), dengan parameter yang diukur yaitu kecerahan, total fosfor serta klorofil-a 
(Shaleh et al., 2014). Hasil pengukuran ketiga parameter tersebut dimasukkan dalam rumus Carlson TSI sebagai berikut :

TSI Kecerahan (SD) $m=60-14,41 \ln$ SD

TSI Klorofil (CHL) ug/l $=30,6+9,81$ ln CHL

TSI Total Fosfor (TP)ug/l=4,15 + 14,2 $\ln$ TP Rata-rata TSI $=\underline{\text { TSI SD }+ \text { TSI CHL + TSI }}$ $\underline{\mathrm{TP}}$ 3

Berdasarkan hasil TSI yang diperoleh, tingkat kesuburan perairan dikelompokkan menurut Carlson (1977) menjadi :
Ultra oligotrofik $(<30)$, Oligotrofik (30-40), Mesotrofik (40-50), eutrofik ringan (50-60), eutrofik sedang (60-70), eutrofik berat (70-80), hipereutrofik (>80).

\section{HASIL}

\section{Status Mutu Perairan}

Kondisi perairan Bengawan Jero dicerminkan oleh nilai konsentrasi beberapa parameter kualitas air baik parameter fisik maupun kimia. Karakteristik parameter fisika dan kimia di Bengawan Jero Kecamatan Turi tercantum dalam Tabel 3.

Tabel 3. Rata-rata parameter fisika dan kimia perairan Bengawan Jero Kecamatan Turi

\begin{tabular}{|c|c|c|c|c|c|c|}
\hline \multirow{2}{*}{ No } & \multirow{2}{*}{ Parameter } & \multirow{2}{*}{ satuan } & \multicolumn{3}{|c|}{ Stasiun } & \multirow{2}{*}{ Keseluruhan } \\
\hline & & & 1 & 2 & 3 & \\
\hline 1 & Suhu & ${ }^{0} \mathrm{C}$ & 29 & 29 & 29 & 29 \\
\hline 2 & Kecerahan & M & 0.317 & 0.207 & 0.173 & 0.23 \\
\hline 3 & DO & $\mathrm{mg} / \mathrm{l}$ & 3.03 & 2.2 & 3.4 & 2.88 \\
\hline 4 & Salinitas & $\mathrm{ppt}$ & 0 & 0 & 0 & 0.00 \\
\hline 5 & $\mathrm{pH}$ & & 8.04 & 8.03 & 8.07 & 8.05 \\
\hline 6 & Nitrat & $\mathrm{mg} / \mathrm{l}$ & 10.3 & 8.63 & 10.3 & 9.74 \\
\hline 7 & Ammonia & $\mathrm{mg} / \mathrm{l}$ & 0.05 & 1.2 & 0.05 & 0.43 \\
\hline 8 & Fosfat & $\mathrm{mg} / \mathrm{l}$ & 0.757 & 0.727 & 0.857 & 0.78 \\
\hline
\end{tabular}

Penilaian kondisi mutu air dilakukan dengan membandingkan angka kualitas air hasil penelitian dengan baku mutu perairan sesuai dengan peruntukannya pada Peraturan Pemerintah Tahun 82 tahun 2001 dengan Metode STORET. Pemanfaatan air di Bengawan Jero antara lain keperluan rumah tangga seperti memasak, mencuci dan mandi; serta di bidang perikanan dan pertanian. Oleh karena itu baku mutu air yang digunakan untuk penentuan mutu air sesuai PP No. 82 Tahun 2001 pada kelas I, II, dan III. Status

Secara umum berdasarkan perhitungan metode STORET yang diperoleh, status mutu air di Bengawan Jero Kecamatan Turi dalam kondisi buruk atau mutu air di Bengawan Jero disajikan pada tabel berikut ini:

Tabel 4. Status mutu air di Bengawan Jero

\begin{tabular}{|c|c|c|c|}
\hline \multirow[b]{2}{*}{ Bengawan Jero } & \multicolumn{3}{|c|}{ Status Mutu Air } \\
\hline & $\begin{array}{c}\text { Kelas } \\
1\end{array}$ & $\begin{array}{c}\text { Kelas } \\
\text { II }\end{array}$ & $\begin{array}{c}\text { Kelas } \\
\text { III }\end{array}$ \\
\hline $\begin{array}{l}\text { Desa Kemlagi Lor } \\
\text { (Stasiun 1) } \\
\text { Desa Pomahan }\end{array}$ & Buruk & Buruk & Sedang \\
\hline $\begin{array}{l}\text { Janggan (Stasiun 2) } \\
\text { Desa Kepudi Bener }\end{array}$ & Buruk & Buruk & Buruk \\
\hline (Stasiun 3) & Buruk & Buruk & Sedang \\
\hline
\end{tabular}

perairan yang tercemar berat pada kelas I dan II . Klasifikasi kelas I merupakan suatu air yang peruntukannya dapat digunakan untuk keperluan air minum dan 
rumah tangga sedangkan kelas II peruntukannya dapat digunakan untuk prasarana/sarana rekreasi air diantaranya mandi dan berenang. Jika melihat dari status mutu airnya yang buruk (tercemar berat) maka air di Bengawan Jero tidak dapat dimanfaatkan langsung oleh masyarakat diperlukan penanganan atau pemulihan. Mutu air yang tidak sesuai dengan baku mutu air minum serta keperluan rumah tangga lainnya akan menyebabkan penyakit bahkan bisa menimbulkan kematian. Menurut Walukow (2010), sekitar 3-4 juta jiwa penduduk dunia meninggal setiap tahun yang disebabkan oleh penyakit waterborne disease, termasuk di dalamnya lebih dari 2 juta jiwa anak meninggal karena diare.

Pada kelas III yang peruntukannya di bidang perikanan dan peternakan, status mutu air di Bengawan Jero dalam kondisi buruk (tercemar berat) di Desa Pomahan Janggan sedangkan Desa Kemlagi Lor dan Kepudi Bener dalam kondisi sedang (tercemar sedang). Kondisi mutu air yang tercemar berat dan sedang mempengaruhi gagal atau menurunnya produksi budidaya ikan. Kandungan oksigen terlarut (DO) yang rendah yaitu berkisar 2,2 mg/l - 3,4 mg/l dengan rata-rata $2,88 \mathrm{mg} / \mathrm{l}$ menyebabkan tidak mendukung untuk dilakukan budidaya ikan secara optimal. Ketersediaan oksigen terlarut dalam badan air sebagai faktor dalam mendukung pertumbuhan, perkembangan dan kehidupan ikan (Sahrijanna \& Sahabuddin, 2014). Menurut Efendi ( 2003), oksigen terlarut yang optimal untuk budidaya ikan berkisar 4-6 mg/l.

Sumber pencemar perairan di Bengawan Jero disebabkan banyaknya limbah rumah tangga, serta limbah pertanian dan perikanan yang menyebabkan tingginya kandungan unsur hara nitrat dan fosfor. Pemberian pupuk kimia saat melakukan penanaman padi yang tidak tepat memberikan dampak buruk pada peningkatan kandungan nitrat. Sofyan et al.,(2011) menjelaskan bahwa konsentrasi nitrat yang tinggi atau melebihi $10 \mathrm{mg} / \mathrm{l}$ seringkali menunjukkan adanya pengaruh kandungan nitrogen yang ada dalam pupuk jika ion $\mathrm{NO}_{3}$ tidak sempurna diserap oleh tanah. Hal ini yang menyebabkan tingginya kandungan Nitrat di Bengawan Jero berkisar $8,63 \mathrm{mg} / \mathrm{l}-10,3 \mathrm{mg} / \mathrm{l}$. Begitupula dengan kandungan fosfat di Bengawa Jero berkisar 0,726mg/l - 0,857 mg/l. Kandungan fosfor yang tinggi biasa berasal dari limbah rumah tangga. Pencemaran yang ditimbulkan oleh limbah domestik (rumah tangga, pasar) dicerminkan oleh tingginya angka nitrat dan fosfat (Walukow,2010).

\section{TINGKAT KESUBURAN PERAIRAN}

Secara umum, tingkat kesuburan perairan di Bengawan Jero berdasarkan nilai Carlson Trophic State Indexs ( TSI) termasuk kedalam kondisi hipereutrofik (Gambar 2) dengan kisaran angka 81-100. Menurut Permen LH No. 28 Tahun 2009 dalam Shaleh et al., (2014), kondisi hipereutrofik merupakan status trofik air yang mengandung unsur hara berkadar sangat tinggi. Status ini menunjukkan air telah tercemar berat oleh peningkatan kadar $\mathrm{N}$ dan P. Kondisi hipereutrofik suatu perairan akan menyebabkan terjadinya penurunan kualitas air dan blooming alga dan tanaman air seperti enceng gondok (Samudra et al., 2013). Permukaan perairan akan dipenuhi tanaman air yang menyebabkan terhambatnya intesitas cahaya matahari dan miskin akan oksigen terlarut sehingga persyaratan hidup ikan sangat kecil atau ikan-ikan akan mudah mati. 


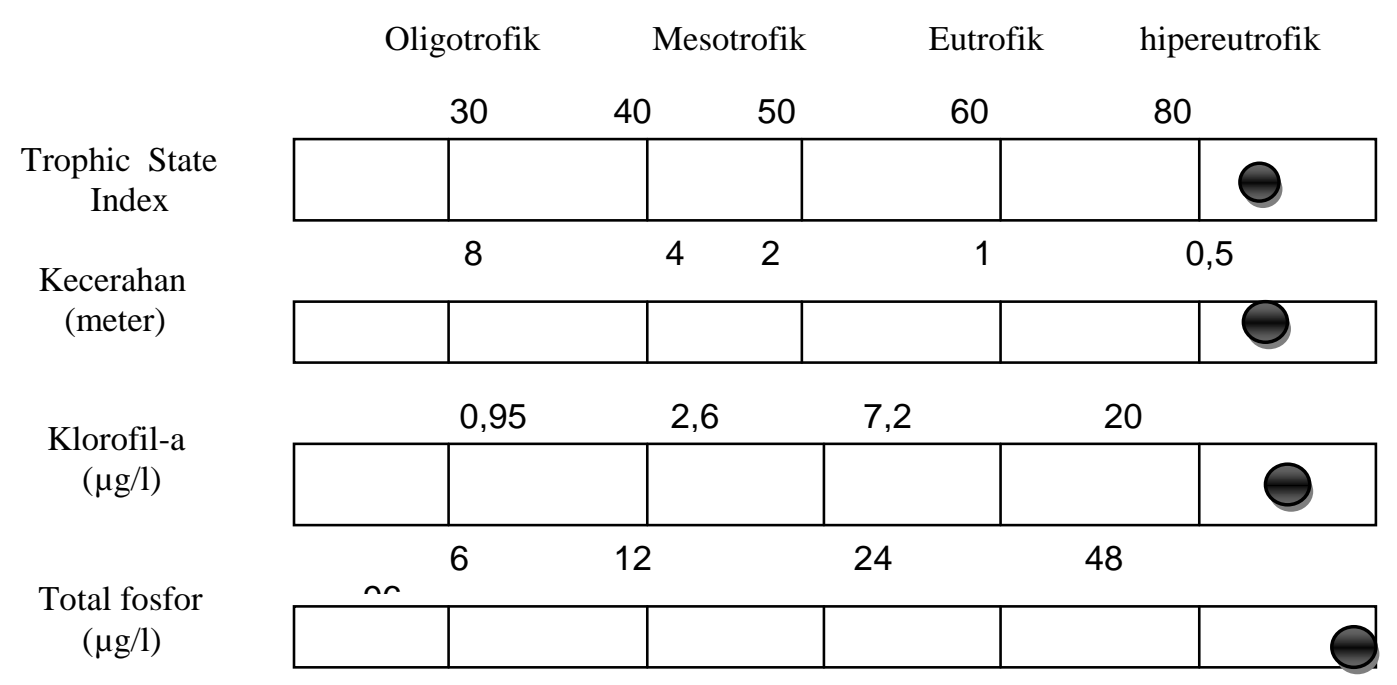

Dengan kondisi hipereutrofik di Bengawan Jero seperti ini maka pengembangan budidaya ikan akan sulit dilakukan. Pengembangan perikanan yang lebih sesuai dengan kondisi ini yaitu perikanan tangkap alami yang diatur sesuai dengan daya dukungnya. Salah satu cara pemulihan Bengawan Jero yaitu dilakukan penebaran ikan pemakan plankton (plankton feeder) atau restoking ikan guna mengurangi dan menanggulangi eutrofikasi di perairan tersebut.

\section{KESIMPULAN}

Status mutu air di Bengawan Jero berdasarkan metode STORET dalam kondisi buruk (tercemar berat) pada Kelas I dan II, sedangkan pada kelas III dalam kondisi sedang (tercemar sedang). Tingkat kesuburan perairan di Bengawan Jero berdasarkan Carlson Trophic State Index (TSI) telah dalam kondisi hipereutrofik atau kondisi dimana unsur haranya sangat tinggi.

\section{SARAN}

Mutu kualitas air yang melebihi batas baku mutu air perlu dilakukan pengolahan atau penyaringan (filter) sebelum digunakan baik untuk keperluan rumah tangga maupun perikanan. Perlunya evaluasi pemanfaatan lahan pertanian secara tepat lestari dengan pemberian pupuk yang tidak berlebihan serta melakukan pra dan pasca produksi yang benar.

\section{DAFTAR PUSTAKA}

Beveridge M. 2004. Cage Aquaculture. Oxford : Blackwell Publishing ltd. USA

Carlson,RE.1977. A trophic state index for lakes.Limnology and Oceanography. 22 (2): 361-369

Efendi, Hefni. 2003. Telaah Kualitas Air bagi Pengelolaan Sumberdaya dan Lingkungan Perairan. Penerbit Kanisius : Yogyakarta.

Keputusan Menteri Lingkunga Hidup Nomor 115 Tahun 2003 tentang Penentuan Status Mutu Air

Peraturan Pemerintah Republik Indonesia No 82 Tahun 2001 tentang Pengelolaan 
Kualitas Air dan Pengendalian Pencemaran Air

Sahrijanna , Andi dan Sahabuddin. 2014.

Kajian Kualitas Air Pada Budidaya

Udang Vannamei (Litopenaeus

Vanammei) Dengan Sistem Pergiliran

Pakan Di Tambak Intensif. Prosiding

Forum Inovasi Teknologi Akuakulture:

313-319

Samudra, Sesilia Rani. Tri Retnaningsih

Soeprobowati dan Munifatul

Izzati.2013. Komposisi, Kelimpahan, dan Keanekaragaman Fitoplankton

Danau Rawa Pening Kabupaten Semarang. BIOMA. Vol 15 (1) :6-13

Shaleh, Fuquh Rahmat . Kadarwan Soewardi dan Sigid Hariyadi. 2014. Kualitas Air dan Status Kesuburan Perairan Waduk Sempor, Kebumen.Jurnal Ilmu Pertanian Indonesia (JIPI). Vol 19(3): 169-173

Sofyan Irwandy, Usman dan Polaris Nasution. 2011. Studi Kualitas Air Untuk Kesehatan Ikan Dalam Budidaya Perikanan Pada Aliran Sungai Kampar Kiri. Jurnal Perikanan dan Kelautan. Vol 16 (1) : 64 -70

Walukow, Auldry F. 2010. Penentuan Status Mutu Air Dengan Metode STORET di Danau Sentani Jayapura Propinsi Papua. Berita Biologi. Vol 10(3) :277281 